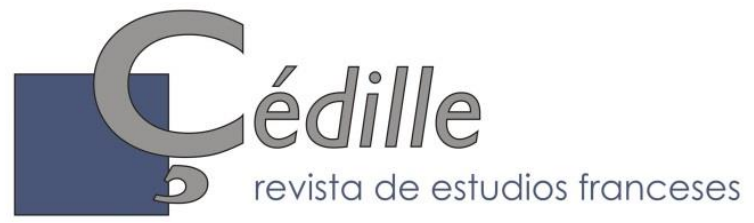

ISSN: 1699-4949

no 20 (otoño de 2021)

Varia

\title{
Michel de Montaigne, traductor de griego. So- bre dos citas griegas y la traducción latina de Conrad Gessner
}

\author{
Antoni BIOSCA i Bas \\ Universidad de Alicante \\ antoni.biosca@ua.es \\ https://orcid.org/oooo-0003-0278-5895
}

\section{Resumen}

Tradicionalmente se le ha atribuido a Montaigne un cierto dominio del griego clásico. Uno de los argumentos es la inclusión en sus ensayos de abundantes citas griegas, algunas de ellas traducidas al francés. Nunca se ha cuestionado que Montaigne empleara antologías para incluir citas clásicas en sus Essais, especialmente la de Estobeo, y que probablemente se ayudaba con la traducción latina de Conrad Gessner que las acompañaban. Algunos casos apuntan a que Montaigne, a la hora de traducir las citas griegas al francés, siguió la versión latina aun cuando discrepaba del original. Estos casos deben ser tenidos en cuenta para poder calibrar mejor el nivel de conocimiento de la lengua griega de Montaigne.

Palabras clave: Estobeo, antología, humanismo, traducción, citas griegas.

\section{Résumé}

On attribue traditionnellement à Montaigne une certaine maîtrise du grec classique. L'un des arguments est l'inclusion dans ses essais d'abondantes citations grecques, dont certaines traduites en français. Il n'a jamais été contesté que Montaigne a utilisé des anthologies pour inclure des citations classiques dans ses $E s$ sais, en particulier celui de Stobée, et qu'il s'est probablement aidé avec la traduction latine de Conrad Gessner. Certains cas suggèrent que Montaigne, lors de la traduction des citations grecques en français, a suivi la version latine même lorsqu'il n'était pas d'accord avec l'original. Ces cas doivent être pris en compte afin de mieux évaluer le niveau de connaissance de la langue grecque de Montaigne.

Mots clé : Stobée, anthologie, humanisme, traduction, citations grecques.

\begin{abstract}
Montaigne has traditionally been attributed a certain mastery of classical Greek. One of the arguments is the inclusion in his essays of abundant Greek quotations, some of them translated into French. It has never been disputed that Montaigne used anthologies to include classical quotations in his Essays, especially of Stobaeus, and that he was probably assisted by the Latin translation of Conrad
\end{abstract}

*Artículo recibido el 26/04/2021, aceptado el 15/06/2021. 
Gessner. Some cases suggest that Montaigne, when translating the Greek quotations into French, followed the Latin version even when he disagreed with the original. These cases must be considered in order to better gauge Montaigne's level of knowledge of the Greek language.

Keywords: Stobaeus, anthology, humanism, translation, Greek quotes.

Es evidente que Michel de Montaigne representa un papel fundamental en la historia de la cultura europea, pues, como humanista ecléctico, supo ejercer de filósofo, escritor, moralista y político. Se le considera, además, el creador del género literario conocido como «ensayo», que precisamente recibió este nombre a partir del término con el que designó a su obra: Essais. Como buen humanista, Montaigne pretendió de alguna manera convertirse en un enlace entre el mundo clásico grecolatino y el moderno, de manera que una parte crucial de su cometido pasó por disponer de amplios y excelentes conocimientos de la cultura clásica. Obviamente este acceso era preferible en las lenguas originales, de manera que el conocimiento de las lenguas clásicas era, sin duda, una cuestión fundamental para Montaigne ${ }^{1}$.

La forma de aprendizaje de la lengua latina seguida por Montaigne es bien conocida por su excepcionalidad ${ }^{2}$. Montaigne se convirtió, de alguna forma, en un extemporáneo hablante nativo de latín, pues, según indica él mismo, fue educado exclusivamente en la lengua del Lacio. Su padre, Pierre Eyquem, que gozaba de un reconocimiento social que le permitiría convertirse en alcalde de Burdeos en 1554, había ordenado que su hijo fuera criado en una pequeña aldea, para que así conociera la humildad de primera mano, donde solo se le hablaría en latín con la finalidad de que aprendiera esta lengua de la misma manera que se aprende una lengua materna. Creemos que, pese a su extensión, es interesante reproducir el pasaje en el que el mismo Montaigne narra esta experiencia:

C'est un bel et grand agencement sans doubte, que le Grec et Latin, mais on l'achepte trop cher. Je diray icy une façon d'en avoir meilleur marché que de coustume, qui a esté essayée en moy mesmes ; s'en servira qui voudra. Feu mon pere, ayant faict toutes les recherches qu'homme peut faire, parmy les gens sçavans et d'entendement, d'une forme d'institution exquise, fut advisé de cet inconvenient, qui estoit en usage [...] il me donna en charge à un Allemand, qui depuis est mort, fameux medecin en France, du tout ignorant de nostre langue, et

\footnotetext{
${ }^{1}$ Para una introducción sobre esta cuestión ver Magnien-Simonin (2007). Sobre los autores latinos citados por Montaigne, ver McKinley (2007). Sobre los autores griegos ver O'Brien (2007).

2 Para el valor de la lengua latina en Montaigne ver Magnien (2007).
} 
tres bien versé en la Latine. Cettuy cy, qu'il avoit fait venir expres, et qui estoit bien cherement gagé, m’avoit continuellement entre les bras. Il en eut aussi avec luy deux autres moindres en sçavoir, pour me suivre, et soulager le premier : ceux cy ne m'entretenoient d'autre langue que Latine. Quant au reste de sa maison, c'estoit une regle inviolable, que ny luy mesme, ny ma mere, ny valet, ny chambriere, ne parloient en ma compagnie, qu'autant de mots de Latin, que chacun avoit appris pour jargonner avec moy. C'est merveille du fruict que chacun y fit : mon pere et ma mere y apprindrent assez de Latin pour l'entendre, et en acquirent à suffisance, pour s'en servir à la necessité, comme firent aussi les autres domestiques, qui estoient plus attachez à mon service. Somme, nous nous latinizames tant, qu'il en regorgea jusques à nos villages tout autour, où il $\mathrm{y}$ a encores, et ont pris pied par l'usage, plusieurs appellations Latines d'artisans et d'utils. Quant à moy, j'avois plus de six ans, avant que j'entendisse non plus de François ou de Perigordin, que d'Arabesque : et sans art, sans livre, sans grammaire ou precepte, sans fouet, et sans larmes, j'avois appris du Latin, tout aussi pur que mon maistre d'escole le sçavoit : car je ne le pouvois avoir meslé ny alteré3.

Nadie dudaría a día de hoy de la eficacia de un método como el recibido por Montaigne, pues con el tiempo los sistemas pedagógicos han tendido a evitar los precepte, fouet o larmes que denuncia, y se ha preferido seguir métodos más próximos al aprendizaje natural de las lenguas. El éxito del método seguido por Montaigne para aprender latín está fuera de duda, pero cabe preguntarse si puede deducirse un éxito similar en el estudio de la lengua griega, tema que ha sido motivo de discusión entre los especialistas4. Podría afirmarse que la opinión general de los estudiosos de Montaigne ha sido que el humanista tenía un nivel moderadamente aceptable de cono-

3 Essais 1, 25. A pesar del interés del debate sobre el valor de las diferentes versiones conservadas de los ensayos y las posibles diferencias entre ellas, hemos tomado todas las citas de la edición de la colección Bibliothèque de la Pléiade, de Gallimard, publicada en 2007. Hemos mantenido las grafías del texto establecido por Jean Balsamo, Michel Magnien y Catherine Magnien-Simonin, que se basan en la edición de 1595. Sobre las diferentes ediciones de los Essais, véase los siguientes trabajos: Desan (2007b); Legros (2007b); Balsamo \& Desan (2007); Balsamo (2007b); Balsamo \& Blum (2007); Balsamo (2007c); DESAN (2007c); Balsamo (2007a); Desan (2007a); Desan (2007d).

4 Para seguir el largo debate sobre los conocimientos de griego de Montaigne, podría ser interesante remontarse a los trabajos ya clásicos de Jean François Payen, Paul Bonnefon, Jean Plattard, Pierre Moreau, Hugo Friedrich, Paul Porteau y Gilbert Highet, todos ellos, por otra parte, recogidos en la bibliografía posterior citada en este trabajo. Como introducción panorámica, véase Legros (2007c). 
cimientos de lengua griega clásica. Es posible que esta consideración proceda de la idea -sea un prejuicio o no-de que alguien tan buen conocedor de la lengua latina no podría ignorar del todo la lengua griega, y menos aún si se trata de una figura de la talla de Montaigne. El propio autor atribuye al griego el mismo valor que al latín en el párrafo que acabamos de citar: c'est un bel et grand agencement sans doubte, que le Grec et Latin.

Hay varios motivos para creer que Montaigne tenía un buen conocimiento de la lengua griega. En primer lugar, sus Essais incluyen numerosas citas de autores griegos clásicos en su lengua original, tema que trataremos más adelante. También se ha argumentado que, cuando Jacques Amyot recibió duras críticas por sus traducciones al francés de la obra de Plutarco, Montaigne salió en defensa de su trabajo, algo que no podría haber hecho un autor que no supiera griego (Knös 1946: 481-482). Del mismo modo, las inscripciones que embellecían las vigas del despacho de Montaigne, y que pueden observarse hoy día, procedían de citas clásicas, y no pocas de ellas están en griego (Legros 2000).

Algunos de estos argumentos merecen ciertas matizaciones. En primer lugar, las citas incluidas en las vigas que adornaban el despacho de Montaigne, procedentes de autores clásicos griegos y latinos, no contienen ninguna traducción y, por tanto, no deberían tomarse como prueba de la inteligibilidad de la lengua griega por parte de Montaigne. Por otra parte, el discurso de Montaigne en defensa de Amyot se centra en la calidad de su uso de la lengua francesa, no en su fidelidad al original griego, por lo que no puede deducirse que Montaigne conociera la lengua griega. El propio Montaigne, en el cuarto capítulo de la segunda parte de sus Essais, lo explica de la siguiente manera:

Je donne avec raison, ce me semble, la Palme à Jacques Amiot, sur tous noz escrivains François ; non seulement pour la naïfveté et pureté du langage, en quoy il surpasse tous autres, ny pour la constance d'un si long travail, ny pour la profondeur de son sçavoir, ayant peu developper si heureusement un autheur si espineux et ferré (car on m'en dira ce qu'on voudra, je n'entens rien au Grec, mais je voy un sens si bien joint et entretenu, par tout en sa traduction, que ou il a certainement entendu l'imagination vraye de l'autheur, ou ayant par longue conversation, planté vivement dans son ame, une generale Idée de celle de Plutarque, il ne luy a aumoins rien presté qui le desmente, ou qui le desdie) mais sur tout, je luy sçay bon gré, d'avoir sçeu trier et choisir un livre si digne et si à propos, pour en faire present à son païs.

Nótese que Montaigne señala que su crítica no procede de sus conocimientos de griego, pues, según afirma, desconoce esta lengua: je n'entens rien au Grec. Obviamente, tal afirmación podría ser una simple muestra de humildad, pero sería extraño que Montaigne recurriera a la modestia en una 
situación en la que sus conocimientos de griego podían servir de garantía de autoridad en su defensa de Amyot. Además, no es esta la única ocasión en que Montaigne afirma de forma clara que desconoce la lengua griega. Sirva de ejemplo el pasaje del ensayo 25 de la primera parte, en el que narra los intentos por parte de su padre de que aprendiera griego de forma lúdica:

Quant au Grec, duquel je n'ay quasi du tout point d'intelligence, mon pere desseigna me le faire apprendre par art. Mais d'une voie nouvelle, par forme débat et d'exercice : nous pelotions nos declinaisons, à la maniere de ceux qui par certains jeux de tablier apprennent l'Arithmetique et la Geometrie. Car entre autres choses, il avoit esté conseillé de me faire gouster la science et le devoir, par une volonté non forcée, et de mon propre desir ; et d'eslever mon ame en toute douceur et liberté, sans rigueur et contrainte. Je dis jusques à telle superstition, que par ce qu'aucuns tiennent, que cela trouble la cervelle tendre des enfans, de les esveiller le matin en sursaut, et de les arracher du sommeil (auquel ils sont plongez beaucoup plus que nous ne sommes) tout à coup, et par violence, il me faisoit esveiller par le son de quelque instrument, et ne fus jamais sans homme qui m'en servist.

Obsérvese que Montaigne afirma nuevamente que sus conocimientos de la lengua griega son muy bajos: Grec, duquel je n'ay quasi du tout point d’intelligence. Otro ejemplo sería el pasaje del ensayo décimo de la segunda parte, en el que Montaigne describe su afición a la lectura y afirma que prefiere leer a los autores clásicos antes que a sus coetáneos, pero que, entre las obras de los primeros, no incluye los libros escritos en griego, ya que su conocimiento de esta lengua es, según dice, puerile et apprantisse:

Si ce livre me fasche, j'en prens un autre, et ne m'y addonne qu'aux heures, où l'ennuy de rien faire commence à me saisir. Je ne me prens gueres aux nouveaux, pour ce que les anciens me semblent plus pleins et plus roides : ny aux Grecs, par ce que mon jugement ne sçait pas faire ses besoignes d'une puerile et apprantisse intelligence.

A pesar de todas estas afirmaciones, que bien pudieran proceder de la modestia de Montaigne, los especialistas han defendido en mayor o menor grado sus conocimientos de griego como parte de su bagaje humanístico. Todas las citas griegas incluidas en los Essais de Montaigne fueron recogidas, traducidas y estudiadas por Börje Knös en un célebre trabajo (Knös, 1946) que resulta imprescindible para conocer el uso del griego de Montaigne, pues recoge las cuarenta y una citas griegas aparecidas en la obra e incluye una introducción sobre el uso del griego del autor y unas conclusiones finales. Entre estas se puede destacar la afirmación de que Montaigne 
poseía amplios conocimientos de griego o, al menos, más de los que él mismo afirmaba:

Tout de même, Montaigne n'a pas été aussi ignorant du grec, qu'il le dit ; on peut le voir dans la défense qu'il fit de la traduction d'Amyot contre ses détracteurs. [...] Il serait trop exagéré de dire, comme le fit Villey, que l'education de son père, quant au grec, aboutit Montaigne à un complet insucces. Il savait lire un peu le grec, sans doute à l'aide de la traduction latine, mais il a compris les phrases et il les a correctement rendues (Knös, 1946: 481-482).

En ese sentido, Knös afirma claramente que Montaigne comprendía bien el griego que citaba y que traducía correctamente bien al francés estas citas. Pese a esto, Knös (1946: 481) reconoce la dependencia de una versión latina en su traducción Nature n'est rien qu’une poésie énigmatique, proce-

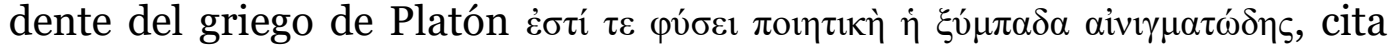
griega que no incluye Montaigne en sus Essais. Esta traducción, según Knös, solo puede comprenderse a través de la versión latina est enim ipsa natura uniuersa poesis ænigmatum plena, traducción de Marsilo Ficino. Más tarde se explicaría que el error procede de que Montaigne confundió ipsa natura con un nominativo, cuando, en realidad, era un ablativo latino (Christodoulou, 1992: 36). Si Montaigne hubiera comprendido la frase de Platón en su lengua original no se habría producido este error. Poco más tarde, en 1952, Linton C. Stevens (1952) detectaría un caso similar al señalar la influencia de una versión latina de la traducción de Montaigne il y a beaucoup de com-

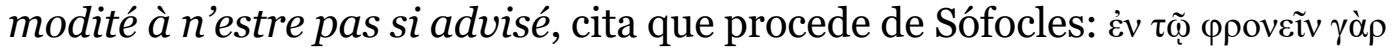

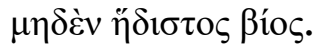

Décadas más tarde Kyriaki Christodoulou (1992) publicó un importante trabajo sobre el uso que hace Montaigne de las citas griegas. En este artículo la autora demuestra que las citas de Montaigne no eran un mero adorno de sus ensayos, sino que constituían una parte importante de su discurso. De la misma manera, la estudiosa localizó algunos pequeños errores en estas citas griegas, algo que atribuye a la forma de trabajar del autor:

Il semble, en effet, qu'il prenait des notes sur les passages qui l'intéressaient dans les sources dont il disposait. A l'heure de les utiliser, et dans la mesure où les passages en question étaient éloignés de leur contexte, il était naturel pour lui de se tromper sur leur sens originel. C'est la seule hypothèse valable qui puisse expliquer ce genre d'erreur chez quelqu'un qui apprit le latin comme sa langue maternelle.

Pocos años más tarde M. A. Screech (1998) publicó un trabajo en el que salían a la luz unas anotaciones marginales autógrafas del propio Montaigne sobre un texto de Lucrecio, algunas de ellas en griego. Un año más tarde, Alain Legros (1999) publicaba un trabajo de título explícito en el que 
se recogían y estudiaban con detenimiento estas anotaciones en griego efectuadas por el propio Montaigne, y años más tarde (Legros, 2010) recuperaría las anotaciones manuscritas de Montaigne. De esta forma, y a pesar de que el humanista francés había mostrado reticencias a la hora de reconocerse como entendido en la lengua griega, se consideraba que estas no eran más que una muestra de su modestia y que, en realidad, Montaigne disponía de un nivel aceptable de conocimientos de la lengua griega:

Kyriaki Christoudoulou, John O’Brien, et avant eux Börje Knös nous ont appris à nous méfier de ce qu'on ne cesse de répéter depuis longtemps sur la base des déclarations mêmes de Montaigne : "Je n'entens rien au Grec ». [...] Les citations grecques des Essais prouvent assez par elles-mêmes que Montaigne a partagé, à une certaine époque de sa vie, l'engouement de ses contemporains pour les auteurs grecs. [...] Qu'à côté de ces érudits, de ces grand lettrés [...] notre auteur estime toutefois « puerile » sa connaissance du grec n'a rien d'étonant. Ne lui fallait-il pas d'ailleurs se débarraser un peu de l'allure « pedantesque » s'il voulait à la fois tenir son rang de gentilhomme et faire œuvre d'auteur de langue française ? (Legros, 1999: 1).

En definitiva, puede concluirse que los sucesivos estudios de las últimas décadas referidos al conocimiento de griego de Montaigne han atribuido al humanista un conocimiento considerable de la lengua griega. Sin embargo, es posible que se pueda aportar más luz sobre esta cuestión partiendo de un punto de vista que, según creemos, no ha sido todavía tenido en cuenta con la debida atención. Nos referimos al estudio de la comprensión de los fragmentos griegos por parte de Montaigne según pueda deducirse a partir de sus propias traducciones y dilucidar, en ese sentido, si es cierta la afirmación de Knös (1946: 482-483) de que Montaigne comprendió bien las frases griegas de sus ensayos y las tradujo correctamente. Al menos, como se verá, hay dos casos que aún no han sido explicados y que merecen la atención de los especialistas en la obra de Montaigne. Debe señalarse que no todas las citas griegas de los Essais aparecen traducidas, ni siquiera la mayoría, pues del total de cuarenta y una citas griegas incluidas en los Essais, solo hemos localizado once ocasiones en que Montaigne las tradujo al francés5. Las reproducimos a continuación, siguiendo el orden de aparición, junto con la localización de la cita, y posteriormente comentaremos los casos más interesantes:

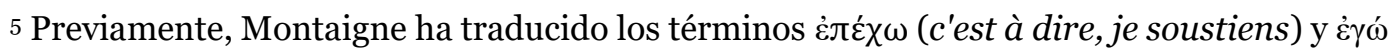
(qui signifie moy) en el capítulo 2, 12 y òvtíxєı (comme qui diroit une autre main) en el 2, 26. Knös (1946: 480-481) demuestra que las referencias a este léxico griego proceden de obras de autores inmediatamente anteriores a Montaigne o coetáneos, como Béroald o Amyot. 


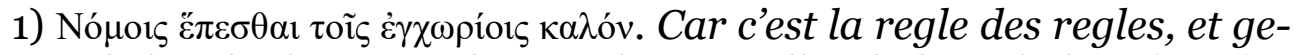
nerale loy des loix, que chacun observe celles du lieu où il est $(1,22)^{6}$.

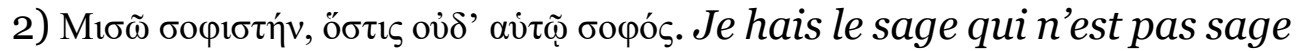
pour soi même $(1,24)$.

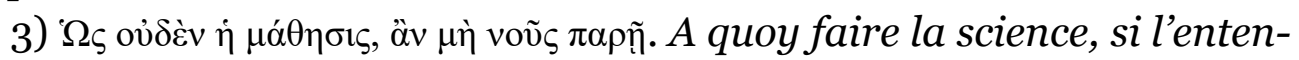
dement n'y est ? $(1,24)^{8}$.

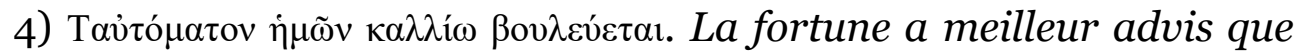
nous $(1,33)^{9}$.

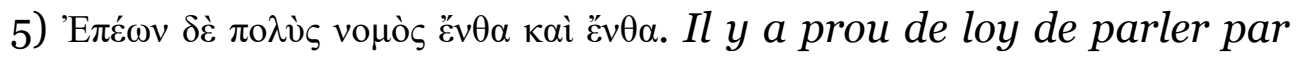
tout, et pour et contre $(1,47)$.

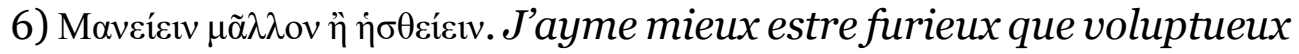
$(2,2)$.

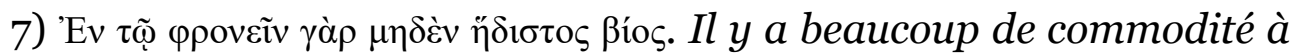
n'estre pas si advisé $(2,12)$.

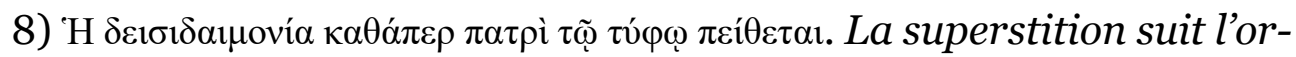
gueil, et luy obeit comme à son pere $(2,12)$.

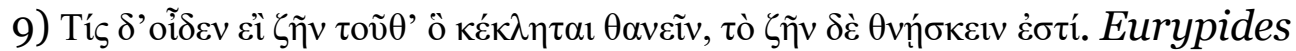
est en doubte, si la vie que nous vivons est vie, ou si c'est ce que nous appellons mort, qui soit vie $(2,12)$.

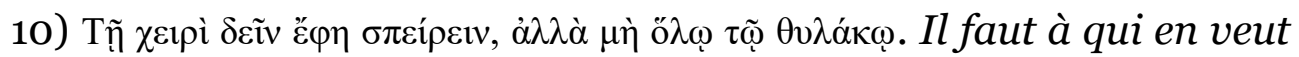
retirer fruict, semer de la main, non pas verser du sac : Il faut espandre le grain, non pas le respandre $(3,6)$.

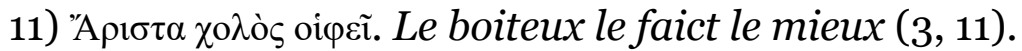

Es posible que en una primera lectura no se adviertan demasiadas diferencias entre el sentido de las citas griegas y sus traducciones al francés. Sin embargo, hay algunas matizaciones que deben ser señaladas. Cuando

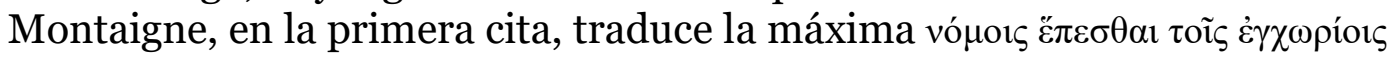

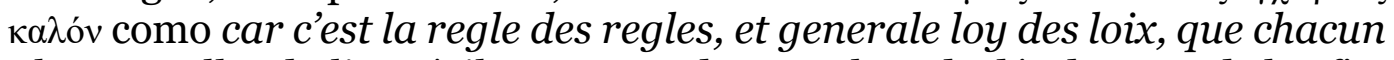
observe celles du lieu où il est, no queda muy claro de dónde procede la afirmación de que esta sea la regle des regles et generale loy des loix, pues esta idea no aparece en absoluto en la cita griega. De la misma manera, en la cita

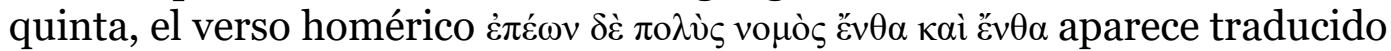
como il y a prou de loy de parler par tout, cuando en realidad no aparece ninguna ley en tal afirmación. La cita sexta, atribuida a Antístenes, $\mu \alpha v \varepsilon i ́ \varepsilon v v$ $\mu \tilde{\alpha} \lambda \lambda$ ov $\ddot{\eta} \dot{\eta} \sigma \theta \varepsilon \dot{\varepsilon} \varepsilon v$, no parece bien comprendida, con la traducción j’ayme mieux estre furieux que voluptueux, ya que la cita griega parece presentar

${ }^{6}$ Capítulo 1, 22, « De la coustume, et de ne changer aisément une loy receüe »; capítulo 1, 23 en las ediciones posteriores.

7 Capítulo 1, 24, « Du pedantisme »; capítulo 1, 25 en las ediciones posteriores.

${ }^{8}$ Capítulo 1, 24, « Du pedantisme »; capítulo 1, 25 en las ediciones posteriores.

9 Capítulo 1, 33, « La fortune se rencontre souvent au train de la raison »; capítulo 1, 34 en las ediciones posteriores. 
infinitivos y no formas verbales personales. Finalmente, el caso quizá más interesante sea el de la cita octava, en el que la relación entre la cita atribuida

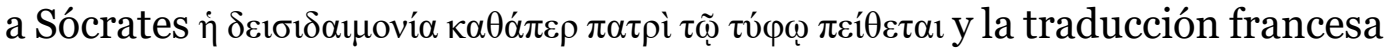
la superstition suit l'orgueil, et luy obeit comme à son pere merece una explicación más detallada.

Es fundamental recordar que en el siglo XVI era muy habitual el recurso a las abundantes antologías y florilegios de citas de autores clásicos que corrían por Europa, como son las antologías de Estobeo, Crispino o demás ${ }^{10}$. Estas obras eran muy útiles para la redacción de un texto erudito, ya que en ellas las citas se clasificaban de forma temática, de manera que los autores modernos podían encontrar con facilidad citas griegas o latinas referidas al tema de su interés. El altísimo número de ediciones de estas antologías muestra el gran éxito que tuvieron en época de Montaigne. Una de las antologías más exitosa fue la realizada por Estobeo, autor tardío que recogió numerosas citas de autores clásicos, cuya obra se publicó por primera vez en latín en 1517 y posteriormente en griego en $1536^{11}$. Si se consulta el número de ediciones de la obra de Estobeo que, según su datación, pudo conocer Montaigne antes de publicar sus Essais, pueden encontrarse las ediciones de $1517,1536,1543,1551,1552,1557$ y 1559 , aunque es posible que haya más. El número de ediciones, como puede observarse, es bastante alto y es una cara demostración del éxito de estos florilegios.

Todos los especialistas reconocen que estas antologías eran consultadas por Montaigne, aunque generalmente se las ha considerado como un simple apoyo a la hora de traducir las citas de los autores clásicos (Knös, 1946: 482; Christodoulou, 1992: 36). En ese sentido, las antologías nunca han sido consideradas como causa de sus errores de traducción del griego al francés. El estudio de la relación entre las citas clásicas de Montaigne y la antología de Estobeo cuenta con la dificultad añadida de que esta última es una obra considerablemente extensa, de manera que no siempre es fácil localizar determinadas citas. Esta localización se ve dificultada, además, por la existencia de numerosas ediciones de la obra a las que pudo tener acceso Montaigne, ya que estas pueden verse ampliadas, reducidas o alteradas en su contenido.

Algunos errores de traducción de Montaigne ya fueron detectados por los especialistas. Es llamativo el caso de la traducción de la cita apare-

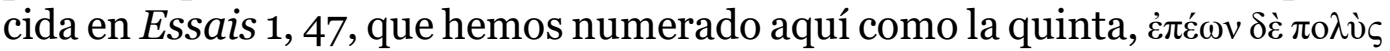

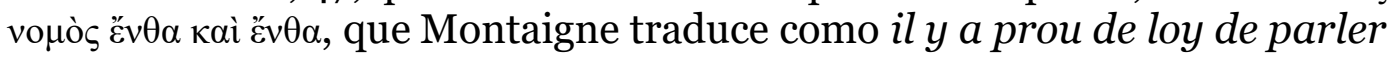
par tout. Este verso homérico significa algo distinto a la versión de Montaigne, pues nada tiene que ver con la ley, sino que viene a referirse a una gran pradera de palabras, aquí y allá, como metáfora de la extensión de un

10 Para el estudio de las antologías de literatura griega clásica y el caso de la obra de Estobeo, véase como punto de partida el trabajo de Campbell (1984).

${ }^{11}$ La edición de Bartolomé Zanetti, Venecia 1536, contiene el texto griego sin traducciones latinas. La portada del libro indica el año 1536, pero el éxplicit indica 1535. 
largo discurso, concretamente el de Eneas ante Aquiles antes del combate ${ }^{12}$. El error de traducción procede de la confusión de las palabras griegas vouós, «extensión, pradera», y vónos, «ley», ya que la segunda forma, que solo difiere en el acento con la anterior, es un término mucho más frecuente en los textos griegos clásicos. Los trabajos de Knös (1946: 472) y Christodoulou (1992: 26) ya habían localizado y comentado este error de traducción. La transmisión de la obra de Homero es de tal magnitud que resulta difícil poder localizar la fuente que pudo leer Montaigne, si es que no fue directamente la Ilíada, pero sí podemos señalar que no nos ha sido posible localizar este verso en las distintas ediciones de la antología de Estobeo ${ }^{13}$.

Christodoulou pudo localizar también un error de transcripción que

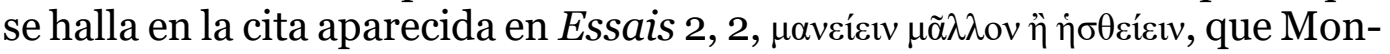
taigne traduce como j'ayme mieux estre furieux que voluptueux. El error que detecta Christodoulou (1992: 25) se refiere a la terminación -દiv de las dos formas verbales, ya que las terminaciones correctas son las del optativo

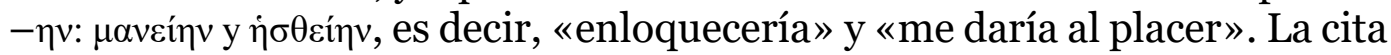
es atribuida por Knös (1946: 472) a varios autores postclásicos, como Diógenes Laercio, Sexto Empírico o Aulo Gelio ${ }^{14}$. Curiosamente, la conversión de los optativos griegos en formas con terminación de infinitivo (-siv), aunque no sean tales, provoca que la oración necesite alterarse en su traducción. Si Montaigne entendió, como parece ser, que $\mu \alpha v \varepsilon i ́ \varepsilon เ v$ y jं $\sigma \theta \varepsilon i ́ \varepsilon v$ eran infinitivos, bien podría haber traducido una oración copulativa con el verbo sobreentendido, construcción sintáctica que, por otra parte, es frecuentísima en griego, «es mejor enloquecer que darse al placer». Sin embargo, Montaigne incluye en su traducción un verbo en forma personal con el sentido de «preferir»: j’ayme mieux. La única palabra de la frase griega que podría haberse entendido como este verbo es el adverbio comparativo $\mu \tilde{\alpha} \lambda \lambda$ ov, «mejor». La traducción de Montaigne, en ese sentido, da un resultado coherente con el sentido original, aunque no sabemos - y es una conjetura que debe tomarse con muchísima prudencia- si Montaigne se pudo dejar llevar por el verbo latino malo, malle, que conocía bien y que significa, precisamente, «preferir».

Como hemos avanzado más arriba hay dos casos que aún no han sido tratados y que, según nos parece, pueden añadir luz sobre la cuestión de los conocimientos de griego de Montaigne.

El primer caso es el de la primera cita de nuestra lista, aparecida en

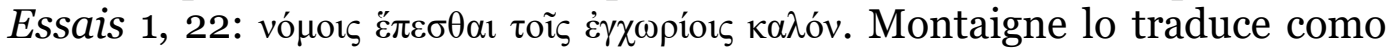

12 Iliada 20, 249. Falta la primera palabra del verso, cuya forma completa es la siguiente:

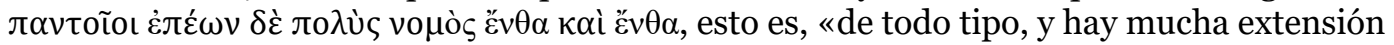
de palabras por aquí y por allá».

${ }^{13}$ Lo mismo afirma Knös (1946: 473), que no localiza la cita en ninguna antología y atribuye como fuente de Montaigne en este caso la Vida de Pirrón $(8,73)$ de Diógenes Laercio.

${ }_{14}$ Concretamente se refiere a Vida de Antístenes 4, 3 Hypotyposeis 3, 23 y Noches Áticas 9,5 respectivamente. 
c'est la regle des regles, et generale loy des loix, que chacun observe celles $d u$ lieu où il est. La cita griega viene a significar, en traducción muy sencilla, «es bueno obedecer a las leyes locales», y parece proceder de los fragmentos de Sófocles ${ }^{15}$. La traducción de Montaigne, por tanto, es perfectamente correcta si la entendemos como una paráfrasis, que chacun observe celles $d u$ lieu où il est, pero resulta extraño el añadido inicial c'est la regle des regles, et generale loy des loix.

Esta cita se encuentra en la antología de Estobeo, quien atribuye su origen a Menandro. Knös la localiza en el capítulo 41 de la edición de 1559 de la antología de Estobeo (1559: 241). Hemos podido localizar la cita, además, en la edición de 1543, en el capítulo 41, titulado De re publica (Estobeo, 1543: 251). No todas las ediciones de la antología de Estobeo contienen traducciones latinas de los fragmentos griegos, pero las ediciones de $1543 \mathrm{y}$ 1559 sí lo hacen, y lo hacen confrontando los textos griegos en las páginas pares y las correspondientes versiones latinas en las impares siguientes, de manera que se pueden consultar a la vez ambas versiones ante el libro abierto. Estas traducciones latinas fueron efectuadas por el conocido humanista suizo Conrad Gessner, según se señala en el título ${ }^{16}$. La traducción latina de esta cita es la siguiente: honestum est leges sequi patrias, donde, nuevamente, puede deducirse el origen de la paráfrasis de Montaigne, pues se aproxima a la traducción francesa que chacun observe celles du lieu où il est. Sin embargo, la versión latina no resuelve el misterio del origen del añadido inicial c'est la regle des regles, et generale loy des loix. Hemos podido comprobar que las distintas ediciones de la antología de Estobeo no son en absoluto idénticas, por lo que el orden y número de citas pueden variar de una edición a otra. Por ello, creemos importante destacar que en la edición de 1543, y no necesariamente en otras, se produce una situación muy curiosa que bien podría explicar el origen del añadido de la traducción de Montaigne. En esta edición de Estobeo aparece justo antes de la cita aquí estu-

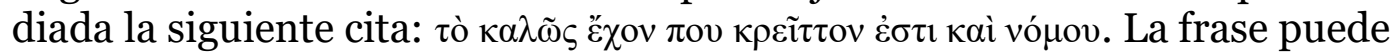
traducirse, de forma muy simple, como «lo que está bien es más importante incluso que la ley». Este verso griego fue traducido al latín por Conrad Gessner de una forma llamativa. Puede observarse que la expresión griega tò

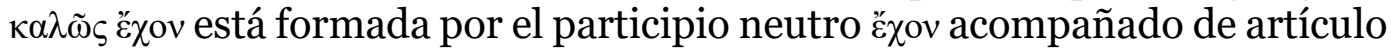
y adverbio, y debe recordarse que el verbo griego que aparece en este sintagma, el verbo ह̌ $\chi \omega$, significa generalmente «tener», pero cuando se ve acompañado de un adverbio, como es este caso, pasa a tener un significado diferente, más próximo al valor copulativo, como «ser» o «estar». Por ello, la expresión griega significa, en traducción muy sencilla, «lo que está bien».

${ }^{15}$ Así lo señala Knös (1946: 470). Efectivamente hemos comprobado que en la edición de Lewis Campbell (1886: 564) de las obras de Sófocles se recoge este verso como fragmento 851.

${ }^{16}$ Como punto de partida para el estudio de la importante figura de Conrad Gessner, véase Wellisch (1984). 
Gessner podría haber empleado el verbo latino sum, el verbo copulativo latino por excelencia, pero prefirió emplear una construcción muy fiel al original griego y empleó el adverbio recte y el verbo habeo, dando como resultado id quod recte habet, etiam lege præstantius est ${ }^{17}$. La frase latina, aunque correcta, recurre a un uso que no es el más frecuente del verbo habeo, de manera que es posible que esta fuera la causa de que Montaigne recurriera a una paráfrasis y no a una traducción literal aun cuando la presenta como una traducción directa del griego. Teniendo en cuenta que las dos citas, tanto en griego como en latín, aparecen seguidas en algunas ediciones de la antología de Estobeo, parece que debe llegarse a la conclusión de que Montaigne recogió la cita griega de la antología de Estobeo y seguidamente consultó la traducción latina de Gessner en la página siguiente para comprender mejor la cita griega ${ }^{18}$. De esta forma incluyó la cita griega vó $\mu$ oı

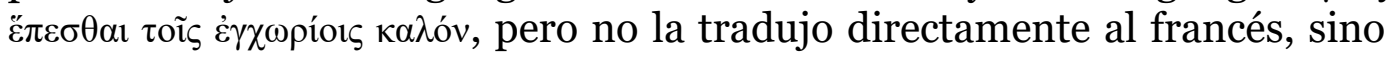
que la tradujo a partir de la versión latina de Gessner, tomando erróneamente la cita anterior como parte de la misma cita: id quod recte habet, etiam lege præstantius est / honestum est leges sequi patrias. La primera parte de la frase latina, por los motivos que ya hemos explicado, debió resultarle llamativa a Montaigne, y quizá por eso prefirió traducirla con cierta libertad de la siguiente manera: c'est la regle des regles, et generale loy des loix. En ese sentido la traducción de Montaigne no procede del griego que cita, sino que se trataría más bien de una versión al francés realizada a partir de dos citas latinas diferentes.

El segundo caso que nos interesa se da en la cita que hemos numerado como octava y que aparece en Essais 2, 12. En este caso, Montaigne

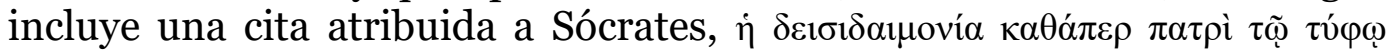
$\pi \varepsilon i \theta \varepsilon \tau \alpha 1$, que traduce como la superstition suit l'orgueil, et luy obeit comme à son pere. La traducción de Montaigne es perfectamente válida, pero úni-

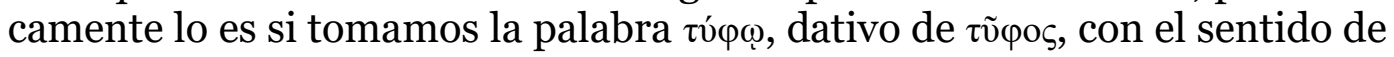
«orgullo». Este término griego significa «humo» en su sentido literal, de

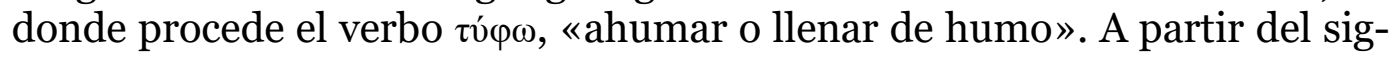
nificado negativo del «humo» como algo molesto que altera la vista o la percepción en general, el griego añadió sentidos figurados como «fiebre», «ilu-

\footnotetext{
17 Este uso del verbo latino habeo con valor similar al de los verbos copulativos ha merecido la atención de los lingüistas desde antiguo. Ya el poeta Giacomo Leopardi (1900: 80) señalaba en 1823 que esta construcción estaba relacionada con la forma impersonal del verbo haber en diferentes lenguas románicas: «E questa forma è tutta greca, giacché presso i greci čx६ıv, la metà delle volte non è altro che un sinonimo di essere, e s'usa in questo senso anche impersonalmente, come in italiano, francese e spagnuolo, tutto dì. Così anche nel greco moderno a ogni tratto. $\Delta \dot{\varepsilon} v$ ع̌ $\chi \varepsilon ı$, non ci è, non ci ha». Para una visión reciente sobre este uso de habeo desde el punto de vista sintáctico véase la entrada «Impersonal habet» de la sintaxis latina de Harm Pinkster (2015: 97).

18 En el caso de la edición de 1543 se trataría de las páginas 250 y 251.
} 
sión», o incluso «ceguera». Es esta última acepción la que creó un significado derivado que entiende la «ceguera» como «incapacidad de ver la realidad tal como es», y de ahí que se pueda entender como «soberbia» u «orgullo», especialmente entre los autores griegos cristianos. Este último sentido es el que incluye Montaigne en su traducción: l'orgueil. Knös localiza esta cita en la edición de la antología de 1559, concretamente en el capítulo o sermo 22 (Estobeo, 1559: 189), la misma en la que ha localizado la cita anterior. Nosotros la hemos encontrado también en la edición de 1543 (Estobeo, 1543: 179), en la de 1551 (Estobeo, 1551: 144v), que solo presenta traducciones latinas, y en la de 1552 (Estobeo, 1552: 304). En todas las ediciones consultadas, la versión latina de Conrad Gessner presenta la traducción latina superstitio superbiæ tamquam parenti est morigera, donde es fácil observar que Gessner ha entendido el término tũyos como superbia, es decir, «soberbia» u «orgullo». En ese sentido, la traducción de Montaigne coincide plenamente con la versión latina de Gessner. Por otra parte, la antología de Estobeo incluye esta cita dentro del apartado De superbia, dedicado obviamente a la soberbia, de manera que se entiende que el sentido de $\tau$ ṽ era aquí precisamente ese: soberbia u orgullo. El propio Montaigne incluyó la cita en un pasaje de los ensayos referido al defecto de soberbia. No cabe duda, por tanto, de que Estobeo, Gessner y Montaigne entendieron $\tau \tilde{v} \varphi \varsigma_{\varsigma}$ como soberbia u orgullo, y así lo tradujo el último al francés: l'orgueil19.

Sin embargo, el significado de $\tau$ vo $\varphi \varsigma$ en esta cita podría matizarse, o incluso valorarse de otra manera, ya que los sentidos figurados o metafóricos solo pueden entenderse en un contexto determinado que lo propicie, y en este caso, al tratarse de una frase suelta, no tenemos contexto de ningún tipo. El verso procede, según Estobeo, de Sócrates, sin que hayamos podido encontrar la cita en la literatura griega clásica, de manera que se trata de un verso aislado cuyo contexto se desconoce por completo. Debe recordarse, además, que el sentido figurado referido al orgullo es particularmente habitual entre los autores griegos cristianos, pero no entre los autores clásicos que recoge Estobeo. Cabe preguntarse si el sentido de la frase original griega era el señalado, es decir, que la superstición sigue sumisamente al orgullo y le obedece como si se tratara de su padre. En principio, no parece demasiado clara la relación entre la superstición y el orgullo. Se trata, en ese sentido, de dos defectos diferentes que no son fáciles de relacionar: la religiosidad vana y la soberbia. Sin el contexto, que aquí es inexistente, no hay ningún argumento que apoye el sentido figurado de un término, de manera que parece preferible entender el significado literal del término griego, que, recordemos, es «humo». Según entendemos, este significado es mucho más acorde al sentido del resto de la frase, pues tiene mucho más sentido considerar que la superstición, es decir, la religiosidad infundada, obedece al humo, es decir, a lo irrelevante, con la sumisión y lealtad con la que un niño

${ }^{19}$ Sobre las reflexiones de Montaigne respecto a la superstición y el orgullo, véase Legros (2008). 
obedece a su padre. En ese sentido, la frase implica una crítica clara de la superstición, al considerar que obedece de forma desproporcionada a hechos que no tienen ningún valor, que son tan vanos e irrelevantes como el humo. De esta manera, nos parece que la cita socrática implica que la

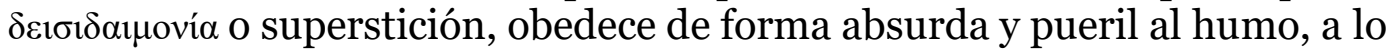
intrascendente, porque se sustenta de forma irracional en rituales vacíos y absurdos, y los respeta y obedece sin rechistar con la contundencia con la que un niño obedece a su padre. Esta parece ser la idea general de la cita griega, que se desfiguró en las traducciones de Gessner y Montaigne por la

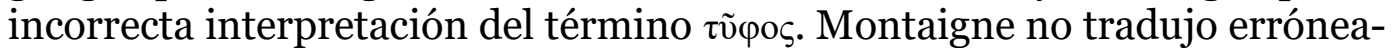

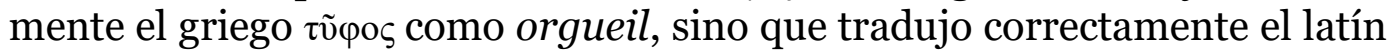
superbia como orgueil. De esta manera, Montaigne incluyó esta cita en un apartado en el que criticaba el orgullo como un defecto, de manera que, teniendo en cuenta que esta cita griega aparecía en la antología de Estobeo en el capítulo titulado De superbia, debe concluirse que Montaigne empleó la antología siguiendo su índice temático para localizar una cita apropiada para el tema que estaba tratando, y a continuación incluyó en sus ensayos una cita en griego que no entendió correctamente y que, en realidad, no se refería al orgullo, para posteriormente traducir al francés el texto latino de Gessner que lo acompañaba. Nuevamente la traducción de Gessner ha sido la causa de la versión francesa de Montaigne.

En definitiva, y tras el estudio de estos dos casos, puede concluirse que el análisis del nivel de conocimiento de la lengua griega de Montaigne, pese a que ha sido objeto de atención entre los especialistas, había pasado por alto el análisis de algunas traducciones del griego al francés aparecidas en sus ensayos. Los investigadores ya habían localizado algunos errores de

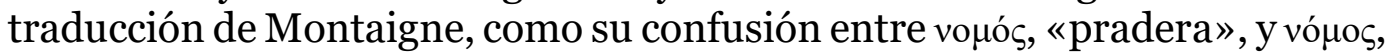
«ley», o su equivocación al entender como infinitivos algunas formas del optativo griego. Según entendemos, las dos citas que hemos estudiado aquí vuelven a demostrar que Montaigne tomaba sus citas griegas a partir de antologías -al menos la de Estobeo- y, lo que es más importante, que las traducía a partir de las versiones latinas de Conrad Gessner, llegando incluso a fundir una cita griega con la traducción al latín de dos citas diferentes o traducir directamente del latín aun cuando difiere del griego. Se trata una información que debería ser tenida en cuenta para calibrar aún mejor los conocimientos de griego de una figura de la indudable magnitud de Michel de Montaigne.

\section{REFERENCIAS BIBLIOGRÁFICAS}

BALSAMO, Jean (2007a): «Exemplaire d'Anvers», in Philippe Desan (ed.), Dictionnaire de Michel de Montaigne. París, Honoré Champion éditeur, 421. 
BALSAMO, Jean (2007b): «Édition de 1588», in Philippe Desan (ed.), Dictionnaire de Michel de Montaigne. París, Honoré Champion éditeur, 350-352.

BALSAMO, Jean (2007c): «Édition de 1598», in Philippe Desan (ed.), Dictionnaire de Michel de Montaigne. París, Honoré Champion éditeur, 358-359.

BALSAMO, Jean \& Claude Blum (2007): «Édition de 1595», in Philippe Desan (ed.), Dictionnaire de Michel de Montaigne. París, Honoré Champion éditeur, 352-358.

BALSAMO, Jean \& Philippe Desan (2007): «Édition de 1587», in Philippe Desan (ed.), Dictionnaire de Michel de Montaigne. París, Honoré Champion éditeur, 348-349.

CAMPBELL, David A. (1984): «Stobaeus and Early Greek Lyryc poetry», in Douglas E. Gerber (ed.), Greek poetry and philosophy: Studies in honour L. Woodbury. Chico, Scholars Press, 51-57.

CAMPBELL, Lewis (1886): Sophocles, vol. II. Oxford, Claredon Press.

Christodoulou, Kyriaki (1992): «Sur le grec de Montaigne». Montaigne Studies, 4, 19-39.

DESAN, Philippe (2007a): «Exemplaire de Bordeaux», in Philippe Desan (ed.), Dictionnaire de Michel de Montaigne. París, Honoré Champion éditeur, 421427.

DESAN, Philippe (2007b): «Édition de 1580», in Philippe Desan (ed.), Dictionnaire de Michel de Montaigne. París, Honoré Champion éditeur, 343-346.

DESAN, Philippe (2007c): «Édition de 1635», in Philippe Desan (ed.), Dictionnaire de Michel de Montaigne. París, Honoré Champion éditeur, 359-361.

DESAN, Philippe (2007d): «Exemplar», in Philippe Desan (ed.), Dictionnaire de Michel de Montaigne. París, Honoré Champion éditeur, 427.

ESTOBEO (1517): Apophthegmata ex uariis autoribus per Joannem Stobæum collecta Varino fauorino camerte interprete. Roma, Iacobum Mazochium.

ESTOBEO (1536): Collectiones sententiarum. Venecia, Vittore Trincavelli.

ESTOBEO (1543): Sententiæ ex thesauris Græcorum delectæ, quarum autores circiter ducentos et quinquaginta citat, et in sermones siue locos communes digestæ, nunc primum a Conrado Gesnero Doctore Medico, Tigurino, in Latinum sermonem traductæ, sicut Latina Græcis e regione respondeant. Zúrich, Gesner.

ESTOBEO (1551): Sententiæ ex thesauris Græcorum delectæ, quarum autores circiter ducentos et quinquaginta citat, et in Sermones sive Locos communes digeste a Conrado Gesnero Doctore Medico Tigurino e Græco in Latinum sermonem traductæ. Amberes, Locus.

ESTOBEO (1552): Sententiæ ex thesauris Græcorum collectæ, quarum autores circiter ducentos et quinquaginta citat, et in sermones siue locos communes digestæ, nunc per Conradum Gesnerum, medicum Tigurinum, Latinitati donata. París, Guielmus Cavellat.

ESTOBEO (1557): Sententiæ ex thesauris Græcorum delectæ, quarum autores circiter CCL citat, et in sermones siue locos communes digestæ, a Conrado Gesnero Doctore Medico Tigurino in Latinum sermonem traductæ. París, Carolus Perier. 
ESTOBEO (1559): Sententiæ ex thesauris Græcorum delectæ, quarum authores circiter ducentos et quinquaginta citat, et in Sermones siue Locos communes digeste, a Conrado Gesnero Doctore Medico Tigurino in Latinum sermonem traductæ, sicut Latina Græcis e regione respondeant. Zúrich, Christophorus Frosch.

KNös, Börje (1946): «Les citations grecques de Montaigne». Eranos. Acta Philologica Suecana, 44, 481-482.

LEgros, Alain (1999): «La main grecque de Montaigne». Bibliothèque d'Humanisme et Renaissance, 61: 2, 461-478.

LEgros, Alain (2000): Essais sur poutres. Peintures et inscriptions chez Montaigne. París, Klincksieck.

LEgros, Alain (2007a): «Annotations de Montaigne», in Philippe Desan (ed.), Dictionnaire de Michel de Montaigne. París, Honoré Champion éditeur, 5358.

LEgros, Alain (2007b): «Édition de 1582», in Philippe Desan (ed.), Dictionnaire de Michel de Montaigne. París, Honoré Champion éditeur, 346-348.

LEgros, Alain (2007c): «Grec (langue)», in Philippe Desan (ed.), Dictionnaire de Michel de Montaigne. París, Honoré Champion éditeur, 511-513.

LEgRos, Alain (2008): "Plutarque, Amyot, Montaigne et la superstition», in O. Guerrier (ed.), Moralia et œuvres morales à la Renaissance. París, Garnier, 275-291.

LEGROS, Alain (2010): Montaigne manuscrit. París, Garnier.

LEOPARDI, Giacomo (1900): Pensieri di varia filosofia e di bella letteratura, v. 5 . Florencia, Successori Le Monnier.

Magnien, Michel (2007): «Latin (langue)», in Philippe Desan (ed.), Dictionnaire de Michel de Montaigne. París, Honoré Champion éditeur, 657-660.

Magnien-Simonin, Catherine (2007): "Antiquité-Ancienneté», in Philippe Desan (ed.), Dictionnaire de Michel de Montaigne. París, Honoré Champion éditeur, 58-59.

MCKInlEY, Mary (2007): "Auteurs latins», in Philippe Desan (ed.), Dictionnaire de Michel de Montaigne. París, Honoré Champion éditeur, 91-93.

Montaigne, Michel de (2007): Les Essais. Edición de Jean Balsamo, Catherine Magnien-Simonin y Michel Magnien. París, Gallimard, Collection Bibliothèque de la Pléiade.

O'BRIEN, John (2007): «Auteurs grecs», in Philippe Desan (ed.), Dictionnaire de Michel de Montaigne. París, Honoré Champion éditeur, 89-91.

PinksTER, Harm (2015): The Oxford Latin Syntax. Vol. 1. Oxford, Oxford University Press.

SCREECH, Michael A. (1998): Montaigne's annotated copy of Lucretius: a transcription and study of the manuscript, notes and pen marks. Ginebra, Droz.

STEVENS, Linton C. (1952): «Montaigne's misinterpretation of a Greek citation». Modern Language Notes, 67: 3, 185-187.

WELLISCH, Hans H. (1984): Conrad Gesner: a bio bibliograpy. Zug, IDC. 